\title{
An 'Open Data' Content Analysis to the Jargons and Metaphor in Pakistani News Bulletin
}

\author{
Taha Shabbir ${ }^{1}$, Sabir Ahmed ${ }^{2}$ \\ FUUAST, Karachi' \\ Greenwich University, Karachi ${ }^{2}$ \\ Email: tahashabbir51@gmail.com
}

\begin{abstract}
Any nation on the planet that wishes to achieve meaningful success must embark on developmental endeavors. They are responsible for maintaining a peaceful sociopolitical environment for their people. It does, however, differ significantly by region and place. Utilizing democratic jargon in news bulletins helps to criticize the stance and provide the public with literary satire. The aim of this research is to show the impact of 'Open Data' on the development of news bulletins. The OD analysis helps news marketers to ascertain the degree to which their bulletin captures the interest of audiences. Pakistan's economy is insufficient to provide the standard of security needed by its citizens. Numerous strategies have been emphasized to achieve this aim, enabling the government to prioritize its people' health. The open data scheme, which allows widespread access to databases, is one of these crucial advancements within Pakistan's architecture. There are online repositories that motivate their users to achieve greater success in existence. It improves their ability to read and comprehend and teaches them to think creatively. Additionally, it allows them to hone their ability to learn and make the requisite compromises to maximize the potential of their talents. Although there is some pressure to use private data sources, it is critical to remember that not all data is safe. As a consequence, individuals must capture and use this type of clear data. The thesis evaluates the benefits and drawbacks of using current data systems inside the newsroom in order to determine their effect on Pakistan's political communication. The use of open data in news analysis allows journalists to work more efficiently; it is important to have immediate access to each item of news. In other words, these structures allow national institutions to operate with a high degree of accountability. Thus, the possibility of encountering an element of inequality in a world capable of wreaking havoc is extremely remote. Open data models are important for innovation and creativity to accelerate. It has been shown that it was instrumental in establishing a trend of revolutionary development that was fuelled by the provision of these facilities. Five privately owned news organizations with the highest scores were selected to gather data. A critical conversation was held to ascertain the words they used to attract interest.
\end{abstract}

Keywords: News Bulletin, Yellow Journalism, Metaphors, Media, News, Slang

\section{INTERFERENCE} Journal of Language, Literature, and Linguistics

\section{E-ISSN: 2721-1835 \\ P-ISSN: 2721-1827}

\author{
Submitted : May 21 ${ }^{\text {th }}, 2021$ \\ Accepted : May $26^{\text {th }}, 2021$
}




\section{INTRODUCTION}

Broadcast TV is a probing medium capable of instilling audiences with a distorted sense of self. This thesis aims to explore the ideological constructions used in Pakistani news headlines and their effect on audiences. This study illustrated ideological structures by applying Fairclough's methodology for critical discourse analysis (CDA) to electronic media news headlines and contrasting three independent Pakistani news sources. Extensive textual research and limited intertextual and sociocultural analysis are conducted and a questionnaire-based evaluation of the effect of news headlines on audiences. The study of Pakistani news articles reveals that they are infused with various philosophies and power relationships. At the same time, audience reactions show their distaste for entertainment-oriented, exaggerated, unjust, and marginally insightful news headlines. The current study is hoped to aid in promoting media literacy among Pakistan's viewers and media authorities.

It is a well-known reality in contemporary society that people rely on various sources of information, including print and electronic media, to stay informed about world events, especially those involving national and international policy, defense, and significant events such as conflict. As a result, there is a need for a diverse news media that will hold audiences informed of global political and social events. However, a study of the research on mainstream media shows that the media influences audience perceptions by upholding its vested interests. Certain philosophies are promoted in the interest of supplying the public with reliable facts. Fairclough (2001) maintains that media debate can be seen as a set of nuanced and conflicting ideological constructions that are not always predetermined in their infrastructure but differ in their constructions.

As a consequence, it is essential to do a more in-depth examination of the politically invested meanings embedded in mainstream media. As a result, a rigorous context is needed to enable a more in-depth review of philosophy, authority, and sovereignty issues. As a result, this study heavily builds on Fairclough's essential discourse analysis (CDA) methodology, emphasizing the three-dimensional examination of every "communicative case." The first degree encompasses in-depth textual and linguistic research; the second level encompasses discursive analysis.

This exploratory study aims to advance research into the headlines of Pakistani electronic media, their framing, and the role of ideology in their news constructions. The mass media is influenced by a variety of socioeconomic, political, economic, and cultural values and structures. According to Fairclough (2001), the newspaper industry is controlled by a small number of institutions with political, cultural, and economic clout. It asserts that political considerations often determine the insightful content of media outputs. This politically driven knowledge has as its objective the replication and reinforcement of patriarchal and exploitative social relations. Additionally, ideology is naturalized on the internet, and the audience sees the media as a conduit of "common sense" knowledge. Thus, Fairclough (2001) argues that, since a variety of cultural institutions can use media, they can never be said to constitute "fact," but rather "representations of facts." 
Fairclough emphasizes the value of media interpretation and claims favoring research that traces audience reception to media texts. How readers "interpret" various texts is almost as important as the study of the underlying philosophies. Additionally, he claims that while politics is not clearly expressed in media discourses, one can still ask about the ideological work that has been performed in any given media. Additionally, the relationship of language usage and authority often remains hazy to the public, leaving them susceptible to being abused or corrupted. A vibrant society needs a free press. It enables individuals to retrieve the knowledge that would be impossible to get otherwise.

Additionally, free media often acts as a watchful protector for the citizens of every world. In terms of the relationship between mainstream media and ideology, it is well acknowledged that media can influence the masses. Different media organizations further the vested interests of a society's "specialized elite" by propagating "false consciousness" to audiences. In Pakistan, the media is known as the state's fourth foundation, besides the legislature, government, and judiciary. Additionally, the right to knowledge is well covered by Pakistan's constitution, which acts as a legal basis for Pakistani media and prohibits anything contrary to Islam, Pakistan's protection, or morality. At the moment, the Pakistani political and social landscape is undergoing significant changes. Pakistan plays a critical role in the global war on terrorism, but the region is still embroiled in several internal disputes.

Similarly, various segments of Pakistan's population often accuse the media of spreading false consciousness among the populace. To this end, the study at hand seeks to elucidate the ideological constructions at work in Pakistani news headlines. The backdrop for this study is given by the press coverage of two significant events in Pakistan by various news outlets. In Pakistan's fast-paced culture, the media is viewed as the fourth pillar of the regime, alongside the legislature, government, and judiciary. Additionally, the right to knowledge is well covered by Pakistan's constitution, which acts as a legal basis for Pakistani media and prohibits anything contrary to Islam, Pakistan's protection, or morality. Pakistan's media landscape has shifted dramatically over the last decade to fifteen years. Pakistani media has thrived since 2002, with the emergence of private Pakistani satellite networks. These networks, though, are only accessible can cable operators. This research aims to decipher the power structures, positions, and personalities propagated by some philosophies in the headlines of Pakistani news channels, the susceptibility of listeners to the linguistic style of news headlines, and the way the environment is framed in these headlines.

The Pew Research Center (a nonpartisan American fact-checking organization) published a report in 2009 on the American public's view of the ideological framing of television news. A survey was conducted between October 23 and October 26 for this reason. According to the findings, the American public chose FOX News as the most politically oriented network, although MSNBC, CNN, NBC, $A B C$, and $C B S$ were all included in the study. Additionally, Machin and Van (2007) argue that discourses are not exclusive to political speeches and reporting. Other than that, they express themselves through the social and material culture 
that shapes our lives, such as entertainment channels such as films, fashion, toys, music, and architecture. Different genres' semiotic tools serve as a portal to various discourses that are further infused by power ties. According to Kress (2009), various semiotic tools have distinct affordances that allow them to be used for a variety of communicative activities, such as when a sound is more useful than a written document.

\section{Research Questions}

1. How ODS can help to detect Political jargons in news?

2. How using ODS can help in formulating the helpful choice of words in news bulletin?

3. How open data system can play role in achieving humor in news?

\section{Research Objectives}

In order to know the answer of how researcher will carry this study it is better to probe into following objectives:

1. Evaluate definition and need of 'Open Data' terms to find reasons.

2. Assess the worth of carrying case study to jargons use in news bulliten

3. Work out a strategy which shows the impact of ODS on relating jargons and its impact on viewer.

4. An 'Open Data' access can prove to be a key that any country can use to assimilate its development purposes.

\section{Research Hypothesis}

H1: A positive relationship exists between social and political development in Pakistan by using open data in making news.

H2: The news organization of a country (Pakistan) can be improved through use of open data system.

\section{Statement of the Problem}

The goal of this research is to add to the body of knowledge about Pakistani electronic media news headlines, their framing, and the presence of politics in their news structures. Many socioeconomic, democratic, technological, and social beliefs and systems affect and are affected by the mainstream media.

\section{LITERATURE REVIEW}

While seeing news bulletin of $9.00 \mathrm{pm}$ the choice of words and jargons are not limited to Urdu language alone. In fact many often English jargons are also included. A language's development and evolution are contingent upon the position it is given in a culture. When languages coexist, they have an impact on one another, yet in the case of English, the universal language; it is exerting control on a large number of other languages (Fareed et al., 2016). English has a disproportionate impact on media debate, especially advertisement discourse. Prior to analyzing the prior literature, it is necessary to describe a few words. Language fusion occurs often in spoken and written text and is variously referred to as "code mixing, code shifting, language alternation, or language interaction". According to 
Alexiadou \& Lohndal (2018), language mixing is often seen as a symbol of laziness and may be detrimental to the wellbeing of a language. Language mixing is a means of communicating multiculturalism and copywriters, journalists, and other writers use it to "convey multicultural perspectives" (Alexiadou \& Lohndal, 2018). Bilinguals demonstrate ingenuity in a variety of forms, one of which is by language mixing. English is often mixed with other languages, and expression and writings often include two or three languages, one of which is the host language and the other of which is a guest language. Bilingual texts include "posters, newspaper posts, ads, and web pages." Multilingual texts include "posters, newspaper articles, advertisements, and web pages". These documents bear witness to a culture's literary traditions. According to the researcher, commercials are a notable illustration of multilingual text since "advertising is an environment where the monolingual standard is occasionally flouted". Advertisements are mostly discussed in this paper as bilingual texts, while some are multilingual, although they are rare and far between. Multilingual and bilingual commercials often have various purposes (Buendía-Castro, 2020; Leimgruber,2017) and elicit a variety of responses from audiences, readers, or customers (Lacroix, 2020). English has risen to enormous popularity as a language of influence, reputation, technology, globalization, and advertisement.

English is granted prominence due to "history, political expediency, and a need for commercial, educational, or technical touch". Watts (2019) used the word "alchemy" to describe how English works in a culture and how it confers prestige on others who use it and broadens one's horizons or cosmopolitanism. Additionally, it is seen as a symbol of modernity and elitism. Stephan-Emmrich (2018) also noted that mixing English demonstrates a cosmopolitan perspective and is a wellestablished practice among teenagers.

A significant context for such advertising is technology, which makes the most common usage in English words in any other background. Not only can the English terms used in bilingual commercials have "memorability" and a sense of humor, they are often "attention-getters", the aim of English in Chinese advertising is to persuade viewers or readers. Additionally, Wright et al. (2021) asserted that the usage of English in Japanese ads reflects the country's "cosmopolitan identity". Wright et al. (2021) argues that while English is a prestige language in Indonesia and is synonymous with elitism, it should not be forgotten that Indonesian regional dialects and languages have historically been associated with identity and national picture. As a result, Wright et al. (2021) concludes that "through the prevalence of English in Indonesian language use, the former would not erode the latter". 


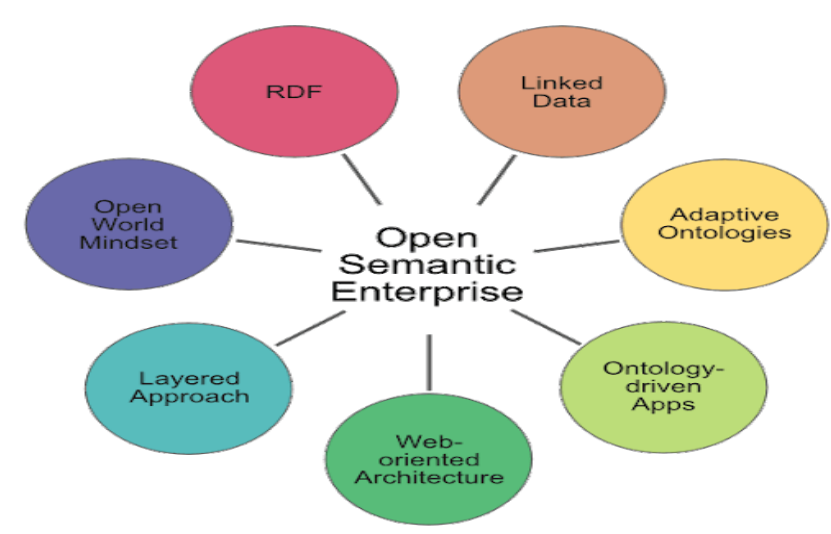

Figure1 : Political Jargons using Open Data

Cable news is an inquisitive tool that has the potential to instill viewers with a twisted sense of self. The aim of this study is to investigate the ideological constructions found in Pakistani news headlines and their impact on readers. This thesis clarified ideological constructions by applying Fairclough's critical discourse analysis (CDA) technique to electronic media news headlines and comparing three different Pakistani news outlets. The text is analyzed extensively, as well as a small amount of intertextual and sociocultural research, as well as a questionnaire-based assessment of the impact of news headlines on readers. Pakistani news stories are infused with a multitude of ideologies and power relationships, while viewer responses demonstrate their distaste for entertainment-oriented, exaggerated, unfair, and moderately informative headlines. It is hoped that this study would contribute to the promotion of media literacy among Pakistan's viewers and media authorities.

It is a well-known fact in contemporary society that people depend on a variety of knowledge outlets, including print and electronic media, to keep informed about global events, especially those affecting national and foreign policy, security, and significant events such as war. As a consequence, a diverse news media is needed to keep people updated of global political and social events. However, a review of literature on mass media reveals that the media exerts control over viewer views through promoting its own corporate interests. Certain ideologies are encouraged in the name of providing accurate evidence to the public. Fairclough (2001) argues that media discourse should be seen as a set of complex and contradictory ideological constructions that are not always fixed in their constructions but also diverge in their constructions. As a result, a more in-depth analysis of the politically charged meanings found in mass media is essential. As a consequence, a robust framework is required to permit a more in-depth study of philosophical, authority, and hegemonic problems. As a consequence, this review heavily draws on Fairclough's critical discourse analysis (CDA) approach, which places a premium on the three-dimensional evaluation of each "communicative event." The first degree is focused on in-depth textual and linguistic study; the second degree is focused on discursive analysis.

\section{Open Data Impacting Media Industry}

Many governments have already provided and opportunity ot its residents 
for accessing the data and information openly. Such as India has adopted the open data India has a governmental portal showing all the necessary information for the general public. At the same time the USA Data.gov is an effective open data source benefiting its residents containing various types of relevant data. In Australia the website data.gov.au provides accessible information to its public. Similarly in New Zealand Data.govt.nz provide lists of various datasets extending help to people and in Pakistan the (data.gov.pakistan) is another useful platform. Open data systems impact the life of people in three major ways that are;

1. Through the use of such systems the government stands more liable than ever before. It makes the government well-organized and the government may become competent by extending effective public services (Zainodin \& Razak, 2020).

2. These systems empower the residents by affecting the lives of citizens directly.

3. The governments can introduce advanced economic opportunities for the people living in the cities and/or remote areas for opening the new industries and sectors.

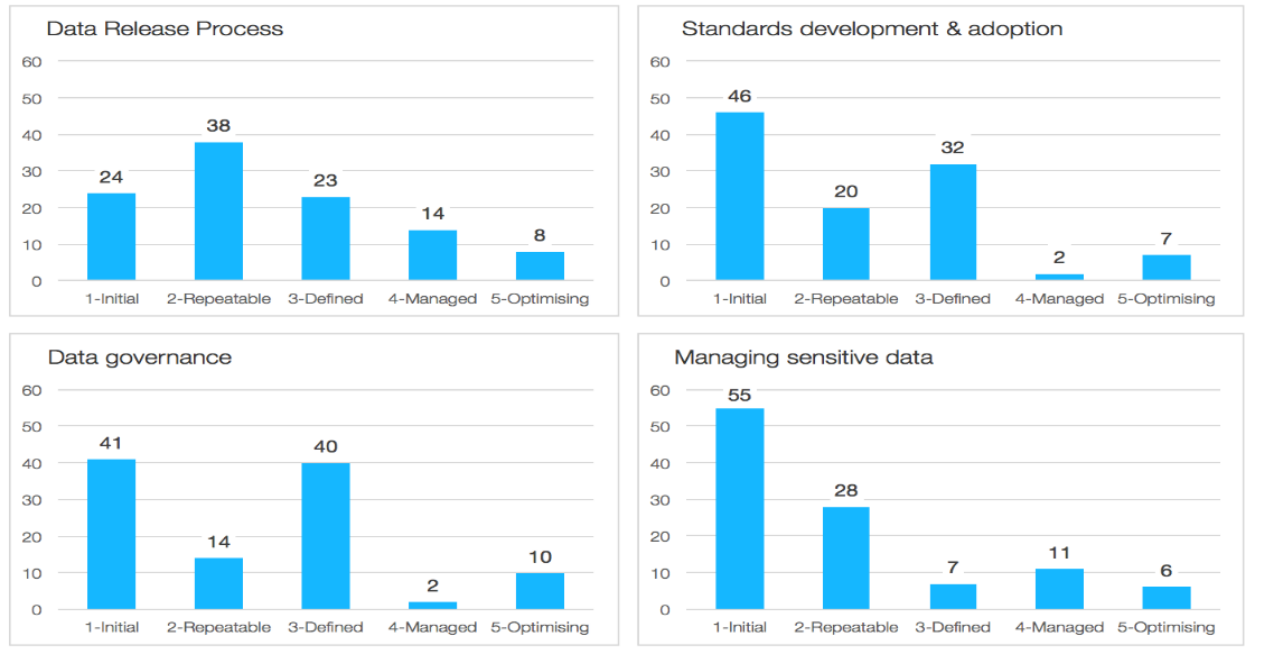

Figure 2: DOI:https://medium.com/@marcelloverona/open-data-impact-alinkography-en-version-a105d70d45b8

\section{THEORETICAL FRAMEWORK}

As discourse analyses follow no framework, therefore the focus keep on finding the humorous in news bulletin. The current research derives its findings from Fairclough's suggested structure for CDA (2001). CDA of media documents entails the examination of the document itself, as well as dialogue and sociocultural practices. According to Fairclough, text review entails a more in-depth examination of language types. He divides text review into four broad categories: vocabulary, syntax, coherence, and text form. Additionally, he calls for the study of three additional principles that are regarded as procedural characteristics of texts and relate further to the analysis of debate experience. These definitions include the power of utterances, the text's coherence, and the text's intertextuality. The third level of study is sociocultural analysis, which entails analyzing the dominant power structures of every culture. The examination of power ties elucidates the hegemonic conflict of the society's people. Additionally, unbalanced power 
dynamics can reproduce, restructure, or undermine existing hegemonies (Fairclough, 2001). Chomsky, Gallego, \& Ott (2019) expanded the concept of media framing in their novel, Media Control: The Spectacular Achievements of Propaganda, by proposing two global models of democracy. According to the first model, democracy prevails where the public has unrestricted access to knowledge and where the methods of dissemination are available and freely accessible to everyone. Whereas, in the second type of government, the methods of communication are carefully and tightly manipulated by a society's "specialized" elite. The mass media has spread to such a degree across the globe that it has developed into a self-contained body capable of subsisting on its own. Chomsky views the mainstream media as a key medium of propaganda dissemination. Additionally, Kellner \& Share (2019) suggests that radio, television, film, and all other forms of media culture are capable of constructing an individual's sense of self, identity, selfhood, race, nationality, sexuality, class, and rank, as well as all other associated conceptions of male and female. The media provides us with critical sources for categorizing others as "us" or "them." "We exaggerate and legitimize the power of the powerful and demonstrate to the weak that they must maintain their positions or face oppression" (Kellner \& Share, 2019). Shoemaker, Johnson, \& Riccio, (2017) makes a case for the commodification of journalistproduced news that can be exchanged, purchased, and exchanged. Additionally, several influences may affect the framing mechanism in the media; some of the more significant factors could include the journalist's personal belief system, expertise, editorial positioning, economic circumstances, political context, cultural conditions, and prevailing ideological structures in society. Hackett \& Zhao (2019) examined how anti-war narratives are covered in the media and discovered that while certain viewpoints are ignored, they eventually find their way into local newspapers. "The public perception of the universe bears just the barest resemblance to reality" (Chomsky, Gallego, \& Ott, 2019) Fairclough claims in his novel, Media Discourse, that media sets an agenda for audiences and thereby establishes its influence. The media's undeniable ability to affect people's perceptions, attitudes, ideals, and social relationships is undisputed. He often attributes media with "signifying force," which is primarily manifested in the way news stories are framed and vocabulary is distorted. Thus, the reasoning for using CDA to examine the ideological construction of Pakistani news headlines is well articulated by the reality that CDA offers an interdisciplinary platform for interpreting large categories of news. As summarized by Fairclough (2001), CDA of news media stories aids in elucidating the study issues. The research's central question is, "How is ideological sense built in Pakistani news bulletin headlines?" On the other hand, small study questions seek to address issues such as "How is the vocabulary distorted by the word choice of Pakistani news headlines?" "How does the way a message is framed in news bulletin headlines affect its impact?" "How is the universe framed and described in news headlines?" "How are the identities and relationships of those interested in a news story established?" and "How receptive are viewers to the news's linguistic style?" CDA has developed into a multidisciplinary field of research as a result of the integration of various methods 
and disciplines. Fairclough has developed his view of discourse by taking together "linguistically focused discourse analysis and related social and political thinking about discourse and expression, in the form of a context appropriate for use in social science research, especially in the study of social change" (Fairclough, 2001). According to Fairclough (2001), debate is both socially constitutive and socially constrained. According to Fairclough, citizens of community are ignorant of the webs of social institutions, political relationships, and the essence of social activities, although their actions have an impact on the social systems and social struggles in their immediate surroundings. The people's view of the media has often been critical for academics, since the public is constantly in touch with the media. Numerous researchers have conducted numerous studies in this region, using both qualitative and quantitative approaches.

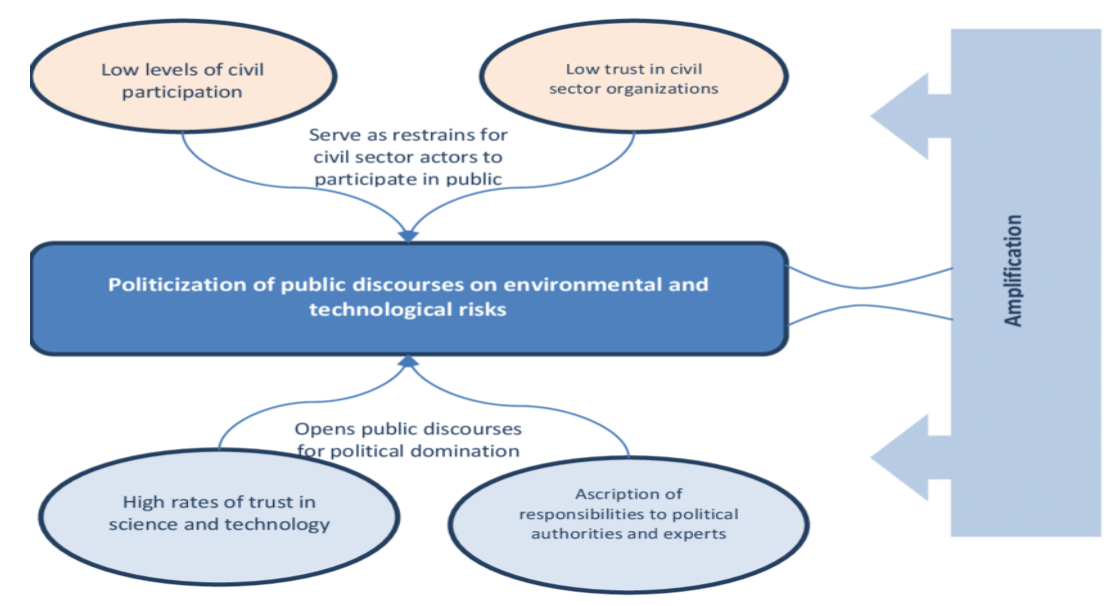

Figure 3: Connection Between Public Opinion and Jargons

\section{METHOD}

A systematic framework is developed to ensure the reliability and quality of this analysis. The current research examines the cultural underpinnings of Pakistani media news stories in order to ascertain their effect on listeners. Qualitative and quantitative studies are conducted to do this. Qualitative research is conducted using Fairclough's method, which relies mostly on textual analysis, taking into account factors such as lexical choices, cohesion, form, bias, and rhetoric in the ARY News, GEO News, and PTV News 9 p.m. news headlines. 608 headlines were reviewed in all. Additionally, the snow ball sampling method is used to elicit feedback from 100 respondents using an online questionnaire designed to ascertain the effect of 9 p.m. news stories on viewers' minds. For qualitative research, the version of CDA (Fairclough, 2001) provides an empirical context by incorporating three distinct levels of analysis that are further connected to three complementary dimensions of debate, namely document analysis, retrieval analysis, and social analysis. However, this study places a premium on textual linguistic study, as well as limited intertextual and sociocultural analysis. A questionnaire is designed for quantitative research with the aim of determining listeners' susceptibility to the linguistic type of news. For the 9 p.m. news briefing, data is gathered from three 
separate Pakistani news sources, namely GEO News, ARY News, and PTV News. The 9 p.m. news update was chosen because this is the moment where the majority of households have the opportunity to relax down during their usual activities and listen to the day's lengthy and comprehensive news report. Transcribing news headlines requires listening to the bulletin. Data were obtained over a period of 20 days, beginning December 1, 2014, and ending December 20, 2014. Each news headline is analyzed separately. Additionally, variables that aid in CDA analysis include lexical preference, harmony, style, bias, and rhetoric. Additionally, quantitative research is used to determine the effect of news reporting and presentation style on audiences. Keeping in mind the concept of polling and surveys of media-related studies, the data collection tool chosen is a survey. Analytical surveys assist in determining the existing state of affairs and in gathering popular sentiment on any given topic. Additionally, they aid in establishing the association between media activities and their effect on media audiences. Participants in this sample range in age from 21 to 31 years. The data is gathered from an online questionnaire. The first query inquires whether respondents listen to the Pakistani news bulletin at 9 p.m. or not. Only certain questionnaires with a yes response to this question are included in the study, which totals 75.33 females and 42 males replied to the questionnaire, bringing their attendance to $44 \%$ and $56 \%$, respectively (see the appendix). Snow ball sampling is used to gather data from these 75 respondents. The questionnaire was completed by respondents in the above age group after it was shared on Facebook. Thus, data are compiled electronically and interpreted further using SPSS tools to build statistical diagrams. After reviewing qualitative and quantitative results, they are combined to answer the primary research question about ideology building in Pakistan's news media headlines.

\section{FINDINGS AND IMPLICATION}

As a result, reporting from the above news organizations are judged on a number of factors, including grammar, continuity, style (politeness, pathos, yelling, pictures, sensationalism, repetitive exclamation, literary exuberance, and music), bias (selection, absence, placement, tone, and word choice), and rhetoric (alliteration, puns, exploring endings, allusions, metaphors).

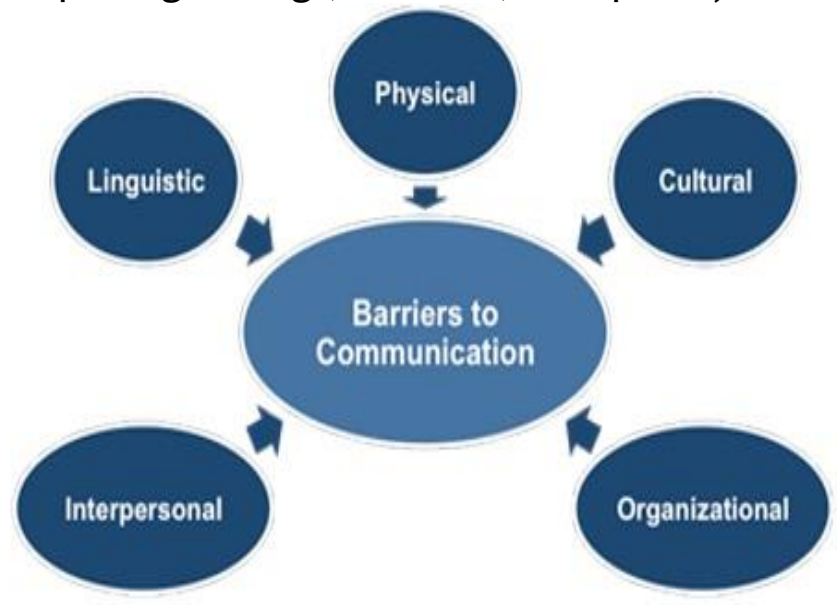

Figure 4: Barriers to Communication by Using Jargons DOI: https://businessjargons.com/semantic-barriers.html 
How is the jargon used in Pakistani news headlines manipulated? The Subsidiary Question is associated with the manipulative nature of news headline lexical items. It has been observed that mass media networks heavily depend on jargon to sway their viewers. To influence viewers' perceptions, figurative language is used. Their language is prejudicial against those people, politicians, and current events. In the majority of cases, fraud is accomplished by the staging of news reports. Additionally, they distort the viewer's perspective by stressing emotion over reasoning. Their self-interest and the channel's organizational practices justify their prejudice. ARY News' stories are anti-government, anti-GEO, and anti-Indian, as shown by their lexical choices. Through their lexical choices, ARY News has framed Imran Khan, the leading opposition symbol, as the only heroic character worthy of saving Pakistani youth from all other corrupt leaders. Throughout their coverage of Imran Khan's sit-in, they repeated phrases such as "Go Nawaz Go." Rana Sana-Allah, a PML-N politician, is dubbed "Gullu Butt" (Gullu Butt is an intertextual reference to the PML-alleged N's party worker captured on camera destroying public property on June 17, 2014). Since then, ARY has used the term "Gullu Butt-ism" to refer to almost every act of torturing innocent citizens. For eg, Lahore will remain closed tomorrow. We will confront Gullu Butts such as Rana Sana-Allah (Federal Law Minister) if they are released. Additionally, ARY News has criticised the PML-N government for elevating Imran Khan's sit-in to a national level by their coverage time and word choice. The participants in the PTI sit-in are praised as "passionate adolescents." Despite the bitter cold, Tehreek-e-Insaaf staff members were fervently engaged (in the sit-in). Females, girls, the elderly, and youth were all enthused by party songs and anthems and danced enthusiastically. Additionally, the government is portrayed as "incapable," "brutal," and "unwanted" in ARY News' 9 p.m. stories owing to their lexical choices. According to reports, the government is pursuing "vengeance" and "punishment" against ARY News for exposing the railway ministry's inefficiency. or, for instance, whenever a batsman reaches a certain number of sixes in a match, the news broadcast often states:

\author{
"Shahid Afridi ka Bharti soormaon Pe laathi charge" \\ "Zardari ne Manzoor Wasan ko lambay sapnay dekhnay London bhej dya." \\ "Sugar Mafia Beqaboo, Qeemtein Aasman se Baatein Karnay Lagein. " \\ "Swat Mein Badlon Ki bambari, Abr e Rehmat dil khol kar basa." \\ "PPP aur Noon League Ki Ank Macholi aur Muk Makao"
}




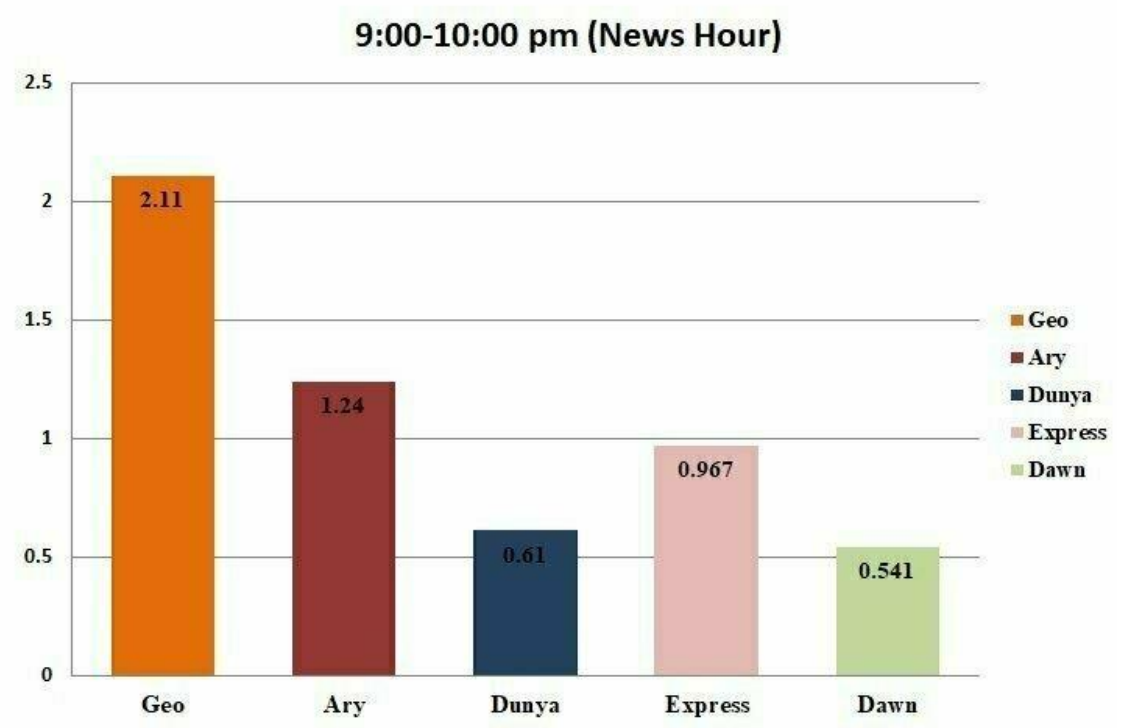

Figure: 4 The Most Watched News Channel in Pakistan

\section{CONCLUSION}

The news media plays a critical role in Pakistan's fast-paced culture. As addressed previously, the presenting style of news, undue commercialization, lack of integrity, unethical and biased reporting, and a lack of self-regulation are some of the major concerns posed by respondents about Pakistani news headlines. As a result, it becomes important for Pakistan's media organizations to demonstrate accountability by enforcing already-existing internal law structures. In Pakistan, the media, as a fourth pillar of the state, has the potential to diffuse the conflicts and intolerance prevalent in different sectors of society. The media authorities in Pakistan have a civic duty to contribute to the country's social unity and prosperity by playing a constructive role. Thus, it is hoped that through self-regulating their respective media networks, Pakistan's media authorities can work to promote unity, solidarity, security, and prosperity in the nation. Fairclough (2001) states that the CDA of every communicative case examines the interaction between three dimensions: text, discourse practice, and sociocultural practice. A far more extensive study of news channels is needed to determine whether or not the same analysis holds valid in that case as well. Additionally, such research can be explicated in such a way that it encompasses the three aspects of text analysis, retrieval analysis, and social analysis in order to provide detailed findings.

\section{REFERENCES}

Alexiadou, A., \& Lohndal, T. (2018). Units of language mixing: a cross-linguistic perspective. Frontiers in psychology, 9, 1719.

Buendía-Castro, M. (2020). Bilingual and multilingual online environmental knowledge resources: A comparative study for translation purposes. International Journal of Lexicography, 33(1), 40-72. 
Chomsky, N., Gallego, Á. J., \& Ott, D. (2019). Generative grammar and the faculty of language: Insights, questions, and challenges. Catalan Journal of Linguistics, 229-261.

Fairclough, N. (2001). Critical discourse analysis. How to analyse talk in institutional settings: A casebook of methods, 25-38.

Fareed, M., Mohd Isa, M. F., \& Wan Mohd Noor, W. S. (2016). Human resource professionals' effectiveness, organizational culture and high performance work system link: evidence from Pakistan. International Review of Management and Marketing, 6(s7), 335-344.

Hackett, R. A., \& Zhao, Y. (2019). 8. Straws in the Wind: Alternatives to the Regime?. In Sustaining Democracy? (pp. 189-222). University of Toronto Press.

Kellner, D., \& Share, J. (2019). The critical media literacy guide: Engaging media and transforming education. Brill.

Kress, G. (2009). Multimodality: A social semiotic approach to contemporary communication. Routledge.

Lacroix, C., Rajaobelina, L., \& St-Onge, A. (2020). Impact of perceived experiential advertising on customers' responses: a multi-method approach. International Journal of Bank Marketing.

Leimgruber, J. R. (2017). Global multilingualism, local bilingualism, official monolingualism: the linguistic landscape of Montreal's St. Catherine Street. International Journal of Bilingual Education and Bilingualism.

Machin, D., \& Van Leeuwen, T. (2007). Global media discourse: A critical introduction. Routledge

Shoemaker, P. J., Johnson, P. R., \& Riccio, J. R. (2017). The gatekeeping of political messages. The Oxford handbook of political communication, 347.

Stephan-Emmrich, M. (2018). 8 Playing Cosmopolitan: Muslim Self-fashioning, Migration, and (Be-) Longing in the Tajik Dubai Business Sector. In Being Muslim in Central Asia (pp. 187-207). Brill.

Watts, R. (2019). Transnational Television Aesthetics. National culture and the 'global'prestige drama (Doctoral dissertation, PhD Thesis, University of Manchester, UK).

Wright, E., Ma, Y., \& Auld, E. (2021). Experiments in being global: the cosmopolitan nationalism of international schooling in China. Globalisation, Societies and Education, 1-14.

Zainodin, W. H. W., \& Razak, M. A. (2020, December). The Role of Government Agency's Employee in Managing Consumer Complaint. In Proceedings of the 4th UUM International Qualitative Research Conference (QRC 2020) (Vol. 1, p. 3). 